\title{
Activating transcription factor 3 , a useful marker for regenerative response after nerve root injury
}

\author{
Hans Lindå ${ }^{1,2 *}$, Mattias K. Sköld ${ }^{1,3}$ and Thomas Ochsmann ${ }^{1}$ \\ ${ }^{1}$ Department of Neuroscience, Karolinska Institutet, Stockholm, Sweden \\ ${ }^{2}$ Neurology Unit, Division of Internal Medicine, Karolinska Institutet, Danderyd Hospital, Stockholm, Sweden \\ ${ }^{3}$ Department of Neuroscience, Section of Neurosurgery, Uppsala University Hospital, Uppsala, Sweden
}

\section{Edited by:}

Thomas Carlstedt, University College

London, UK

Reviewed by:

Steve N.S. Cheung, University of

Tasmania, Australia

Peter Shortland, Barts and The London

School of Medicine and Dentistry, UK

*Correspondence:

Hans Lindå, Neurology Unit, Division of Internal Medicine, Karolinska

Institutet, Danderyd Hospital,

Stockholm, Sweden.

e-mail: hans.linda@ki.se
Activating transcription factor 3 (ATF3) is induced in various tissues in response to stress. In this experiment, ATF3 expression was studied in adult rats subjected either to a dorsal or ventral root avulsion (VRA; L4-6), or sciatic nerve transection (SNT). Post-operative survival times varied between $1.5 \mathrm{~h}$ and 3 weeks. In additional experiments an avulsed ventral root was directly replanted to the spinal cord. Dorsal root ganglias (DRGs) from humans exposed to traumatic dorsal root avulsions were also examined. After SNT ATF3 immunoreactivity (ATF3 IR) was detected in a few DRG neurons already $6 \mathrm{~h}$ after the lesion. After $24 \mathrm{~h}$ the number had clearly increased and still at 3 weeks DRG neurons remained labeled. In the ventral horn, ATF3 IR in motoneurons (MN) was first detected $24 \mathrm{~h}$ after the SNT, and still 3 weeks post-operatively lesioned MN showed ATF3 labeling. After a VRA many spinal MN showed ATF3 IR already after $3 \mathrm{~h}$, and after $6 \mathrm{~h}$ all MN were labeled. At 3 weeks a majority of the lesioned MN had died, but all the remaining ones were labeled. When an avulsed ventral root was directly replanted, MN survived and were still labeled at 5 weeks. In DRG, a few neurons were labeled already at $1.5 \mathrm{~h}$ after a dorsal root avulsion. At $24 \mathrm{~h}$ the number had increased but still only a minority of the neurons were labeled. At 3 days the number of labeled neurons was reduced, and a further reduction was at hand at 7 days and 3 weeks. In parallel, in humans, 3 days after a traumatic dorsal root avulsion, only a few DRG neurons showed ATF3 IR. At 6 weeks no labeled neurons could be detected. These facts imply that ATF3 response to axotomy involves a distance-dependent mechanism. ATF3 also appears to be a useful and reliable neuronal marker of nerve lesions even in humans. In addition, ATF3 up-regulation in both motor and sensory neurons seems to be linked to regenerative competence.

Keywords: ATF3, nerve lesion, motoneuron, dorsal root ganglia, regeneration, spinal cord

\section{INTRODUCTION}

Activating transcription factor 3 (ATF3) is induced in various tissues in response to stress (Chen et al., 1996). It regulates transcription by binding to DNA sites with Jun proteins as a homodimer, which represses transcription, or as a heterodimer, which activates transcription (Chen et al., 1994). ATF3 reacts as an immediate-early gene, i.e., it encodes transcription factors that control specific target genes whose products regulate main functions in the immediate response to injury, and for the neurons the metabolic machinery is principally turned to survival and regeneration (Sheng and Greenberg, 1990). ATF3 is closely related to c-Jun and belongs to the same superfamily of transcription factors. C-Jun is one of the best studied immediate-early genes and it has been shown to be induced after both motoneuron and dorsal root ganglias (DRG) neuron injury (Herdegen et al., 1991; Leah et al., 1991), and the time-course for the induction is distancedependent (Kenney and Kocsis, 1997a). ATF3 is also induced in a distance-dependent manner after axotomy in spinal motoneurons (MN) and DRG neurons (Tsujino et al., 2000). However, c-Jun and ATF3 expression differs in that only c-Jun is expressed in intact MN and DRG neurons, is trans-synaptically induced, and is induced in different subpopulations of DRG neurons (Herdegen et al., 1991; Leah et al., 1991). The actual mechanisms regulating ATF3 expression are unknown, but it has been shown that both nerve growth factor (NGF) and glial cell line-derived neurotrophic factor (GDNF) can influence ATF3 expression. Intrathecal delivery of NGF or GDNF clearly reduced the number of DRG neurons expressing ATF3 after axotomy (Averill et al., 2004). In parallel, reinnervation of the muscle after a crush lesion, and thus normalizing the retrograde transport of growth factors, also seemed to down-regulate ATF3 expression (Kataoka et al., 2007). Similar to c-Jun, the trigger signal for ATF3 appears to be a negative signal (Leah et al., 1991), i.e., interruption in the axon of the retrograde transport of molecule(s) that probably are growth factors. In vitro studies have also shown that NGF depletion can induce ATF3 expression (Mayumi-Matsuda et al., 1999). The physiological function of ATF3 expression is unknown but the same growth factor treatment that has been shown to reduce cell death and promote regeneration of lesioned neurons also will reduce ATF3 expression (Rich et al., 1987, 1989). In PC12 cells and 
superior cervical ganglion cells, ATF3 has been shown to induce the anti-apoptotic factor heat shock protein 27 and to act together with c-Jun to reduce cell death and promote neurite outgrowth (Nakagomi et al., 2003). Regulation of ATF3 expression in a strict distance-dependent manner has also been shown for corticospinal neurons, which up-regulate not only ATF3, but also other growthassociated molecules, following intra-cortical axotomy but not after a distant spinal axotomy (Mason et al., 2003). It has also been shown that ATF3 is up-regulated in Schwann cells during Wallerian degeneration, thus playing a role in preparing the distal segment of injured axons for regeneration (Hunt et al., 2004). However, ATF3 may have dual roles, which has been shown in ALSSOD1 transgenic mice where ATF3 expression preceded death of spinal MN (Vlug et al., 2005).

In the present study, the aim has been to investigate if ATF3 induction in injured $\mathrm{MN}$ and primary sensory neurons correlates to the regenerative response. The animal lesion models used in the present study are clinically relevant and were selected because the regenerative capacity, as well as the degree of cell death, of lesioned neurons are completely different and have previously, to some extent, been described. The aim has also been to explore if human DRG neurons express ATF3 after nerve lesions.

\section{MATERIALS AND METHODS}

Adult female Sprague-Dawley rats were anesthetized with a mixture of midazolam (Dormicum, Roche Diagnostics; $1.25 \mathrm{mg} / \mathrm{ml}$ ) and a combination of fentanyl citrate $(0.08 \mathrm{mg} / \mathrm{ml})$ and fluanisone ( $2 \mathrm{mg} / \mathrm{ml}$; combined in Hypnorm, Janssen). The mixture was given i.p. The animals were either subjected to a unilateral sciatic nerve transection (SNT) just below the obturator tendon followed by a resection of a $10 \mathrm{~mm}$ long segment of the nerve, or a laminectomy was performed followed by an avulsion of the L4-6 ventral or dorsal roots from the surface of the spinal cord. The animals were sacrificed with an overdose of pentobarbital after 1.5, 3, 6, $24 \mathrm{~h}, 3$, 7 days, 3 weeks post-operatively. Three animals from each of these survival times and lesion types were included. Spinal cord segment L4-6 and corresponding DRGs were then removed. To verify that the ventral and dorsal root avulsions (DRA) had been made properly in the segments analyzed, the spinal cords were carefully examined after death in a dissection microscope to make sure that the roots had been torn off at the very exit from the spinal cord surface. In naive control rats no operation was performed. In three sham-operated controls at each survival time, overlaying skin and paraspinal muscles were removed, but no laminectomy was performed. Four naive control animals were also used. In all experiments, labeled neurons with a visible nucleus at the lesioned side were counted and compared with the total number of neurons from the same side. All neurons, i.e., MN and DRG neurons, were counted in photomicrographs taken from three randomly chosen sections at least $28 \mu \mathrm{m}$ apart of the spinal cord or DRG, respectively, in each animal at all survival times. As for the motoneurons, only neurons located in the lateral motor nucleus (Rexed's lamina IX) were included. After ventral root avulsion (VRA), also the total number of $\mathrm{MN}$ on the lesioned side was calculated and compared with the total number on the unlesioned side. Five sections, at least three sections apart, of the spinal cord were evaluated. In three animals, L4-6 ventral roots were avulsed and the L4 root was directly replanted. Calculations in these experiments were made in a similar way as after avulsion without replantation. Also DRGs from humans, 3 days and 6 weeks after a traumatic DRA were examined. In these DRGs, the number of ATF3 labeled neurons was calculated in five sections at least three sections apart. In all experiments, fresh frozen tissue was cut in $14 \mu \mathrm{m}$ thin sections on a Cryostate (MICROM HM 560, Heidelberg, Germany) and thawed onto chrome alum-gelatine treated slides. The sections were soaked in $0.01 \mathrm{M}$ PBS buffer for $10 \mathrm{~min}$ and incubated overnight in a humid chamber at $4^{\circ} \mathrm{C}$ with either rabbit polyclonal anti-ATF3 sc-188, 1:100 (Santa Cruz Biotechnology, Inc. California, USA) or in combination with mouse monoclonal antiPan Neurofilament 18-0171, 1:200 (Zymed Laboratories, INC, San Francisco, USA). Antibodies were diluted in 0.01 PBS containing $5 \%$ donkey serum, $5 \%$ bovine serum albumin, $0.3 \%$ triton and $0.1 \%$ sodium azide. The best result with the antibody was achieved when the sections were fixed/permeabilized in ice cold $99.5 \%$ acetone for $10 \mathrm{~min}$ and rinsed in $0.01 \mathrm{M}$ PBS buffer for two times $5 \mathrm{~min}$ before incubating with the antibody. Next day the slides were rinsed two times $10 \mathrm{~min}$ in $0.01 \mathrm{M}$ PBS buffer and incubated with a secondary antibody anti-rabbit CY3 (Jackson ImmunoResearch Laboratories, Inc, USA, product no. 715-165-151) diluted 1:400 or in combination with anti-mouse CY2 (Jackson ImmunoResearch Laboratories, Inc, USA, product no. 711-225-152) diluted 1:400. All secondary antibodies were diluted in 0.01 PBS buffer with $0.3 \%$ triton and $0.1 \%$ sodium azide. After the slides were rinsed in PBS buffer, they were mounted in a mixture of glycerol and PBS (1:3), and coverslipped. The sections were examined and photographed in a Nikon Eclipse E600 microscope equipped with epifluorescence and appropriate filter combinations for the fluorophores used here. Statistics was calculated with Kruskal-Wallis test (Prism software). The number of labeled neurons (median) showed significant variation $(p<0.05)$ in all lesion types.

\section{RESULTS}

After SNT, ATF3 immunoractivity (ATF3 IR) was detected in $1.3 \%$ (median) of DRG neurons already $6 \mathrm{~h}$ after the lesion. After $24 \mathrm{~h}$ $55.4 \%$ of the DRG neurons were labeled (Figure 1A; Table 1). No clear change in the number of labeled neurons could be seen at other survival times ( 3 days to 3 weeks, Table 1). After a DRA, $1.3 \%$ of DRG neurons were labeled already at $1.5 \mathrm{~h}$ and no change could be seen at 3 and $6 \mathrm{~h}$ post-operative survival times (Figure 1B; Table 1). At $24 \mathrm{~h}$ the number of labeled neurons had increased to $19.0 \%$ (Figure 1C), but were still much fewer than after a SNT at this survival time (Table 1). The number then decreased from 3 days $(4.2 \%)$ to 3 weeks $(0.6 \%)$ post-operatively (Table 1).In humans, after a traumatic DRA, ATF3 labeling was only seen in $3.6 \%$ of DRG neurons after 3 days (Figure 1D), and at 6 weeks no labeling could be detected. In the ventral horn, ATF3 labeling in $\mathrm{MN}$ was first detected $24 \mathrm{~h}$ after a sciatic nerve transaction, and at this time $59.5 \%$ of the $\mathrm{MN}$ were labeled (Figure 2A; Table 1). No labeling could be seen in contra-lateral unlesioned $\mathrm{MN}$ (Figure 2B). At 3 days and 3 weeks the number of labeled $\mathrm{MN}$ was not changed. Already $3 \mathrm{~h}$ after a VRA $33.5 \%$ of the spinal $\mathrm{MN}$, which were often located in the ventral part of the motor nucleus, showed ATF3 labeling (Figure 2C), and after $6 \mathrm{~h}$ all MN, including axial MN, were labeled (Table 1). At 24 h, 3 and 7 days 


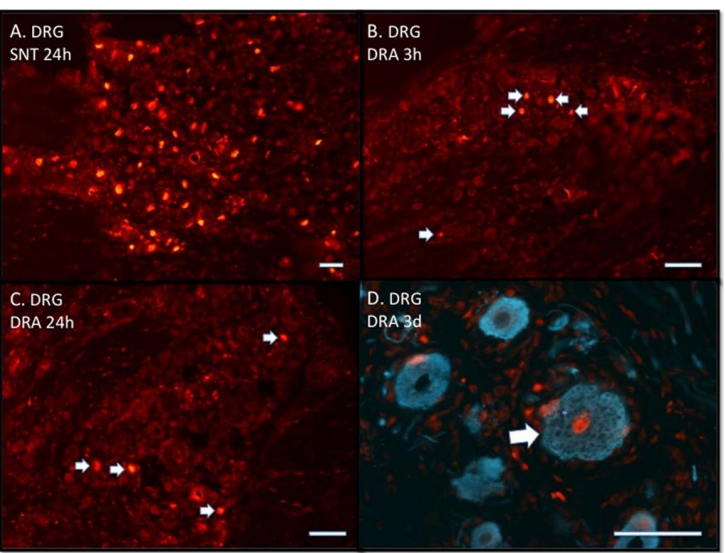

FIGURE 1 | (A-D) Immunofluorescence photomicrographs stained with ATF3 antibodies showing dorsal root ganglia (DRG) after sciatic nerve transection (SNT) or dorsal root avulsion (DRA). Note that ATF3 labeling is localized in the nuclei. (A) Shows that the majority of the neurons are labeled $24 \mathrm{~h}$ post-operatively. (B) Shows a few labeled neurons (arrows) already after $3 \mathrm{~h}$. (C) Shows that at $24 \mathrm{~h}$ there are still only a few labeled neurons (arrows). (D) Shows a labeled (arrow) human DRG neuron three days after a traumatic DRA. (D) Double labeled with neurofilament antibodies. Scale bars $50 \mu \mathrm{m}$ (A-D).

(Figure 2D), all MN were still labeled and no significant cell death was at hand. At 3 weeks, however, a majority of the MN (66.5\%) had died but the few remaining ones were all labeled. After a direct replantation of an avulsed ventral root no significant cell death, and still ATF3 labeling, was seen among spinal MN at 5 weeks post-operatively (Figures $3 \mathrm{~A}-\mathrm{C}$ ). In sham-operated controls, at all survival times, no motoneuron labeling could be seen in the lateral motor nucleus. In DRG after sham operation, only very few labeled neurons $(<1 \%)$ could be seen with no significant change in number at different survival times. In naive control rats, no ATF-3 labeling could be detected in DRG neurons or MN.

\section{DISCUSSION}

In this study we found that ATF3 expression after nerve lesion has many similarities with c-Jun. Both ATF3 and c-Jun (Herdegen et al., 1991; Leah et al., 1991) are up-regulated in DRG neurons and $\mathrm{MN}$ after a peripheral axotomy. After a dorsal root lesion, both ATF3 and c-Jun are transiently up-regulated in DRG neurons (Kenney and Kocsis, 1997b). After a VRA, c-Jun is in parallel with ATF3 up-regulated in virtually all MN but, in contrast to ATF3, c-Jun labeling will disappear already after approximately one week (Wu, 1996; Piehl et al., 1998). Also GAP-43, another marker linked to regeneration, has the same profile of expression as ATF3 in response to axonal lesions. In DRG neurons, GAP-43 response is much stronger after a peripheral axotomy than after a dorsal root transection (Chong et al., 1994), and in MN a clear response can be seen both after a peripheral axotomy and a ventral root transection (Lindå et al., 1992a). GAP-43 up-regulation is also, in parallel with ATF3, sustained for a longer time in $\mathrm{MN}$ after a ventral root lesion than c-Jun (Piehl et al., 1998).

Our study also showed that ATF3 is up-regulated in a strict distance-dependent manner.ATF3 was detected in lesioned DRG neurons earlier than in spinal MN after a SNT. In MN, labeling could be seen earlier after a VRA than after a SNT. In DRG neurons, labeling was seen earlier after a DRA than after a SNT. All these results strongly imply a distance-dependent regulation of ATF3 expression. A similar result has also been described when spinal nerve and sciatic nerve cut was compared (Tsujino et al., 2000). These results indicate that the regulation of ATF3 expression probably involves interruption of the retrograde transport of molecules in the axon. These molecules are probably neutrophins, which has been shown to down-regulate ATF3 expression in both DRG (Averill et al., 2004) and MN (Parsadanian et al., 2006). In mouse MN, GDNF will down-regulate ATF3 expression and up-regulate c-Jun after nerve avulsion, and at the same time promote neuronal survival (Parsadanian et al., 2006). GDNF will also up-regulate c-Jun and promote survival of avulsed rat MN (Wu et al., 2003). Also BDNF will promote motoneuron survival after VRA (Novikov et al., 1995). In line with these results, in this study we demonstrated that replantation of an avulsed ventral root, which probably will provide $\mathrm{MN}$ with neurotrophins from the replanted root, promoted survival of lesioned MN. Moreover, the surviving MN were all expressing ATF3. Motoneuron regeneration after replantation of an avulsed ventral root has previously been described (Carlstedt et al., 1986; Cullheim et al., 1989; Chai et al., 2000; Hoang and Havton, 2006). Increased survival of $\mathrm{MN}$ after replantation of an avulsed ventral root has also been

Table 1 Showing the median (range) of the ratio (\%) between ATF3 labeled and total number of MN and dorsal rot ganglia neurons after different types of nerve lesions.

\begin{tabular}{lllll}
\hline Survival times & $\begin{array}{l}\text { Moto-neurons. } \\
\text { Ventral root avulsion }\end{array}$ & $\begin{array}{l}\text { Dorsal root ganglia. } \\
\text { Dorsal root avulsion }\end{array}$ & $\begin{array}{l}\text { Moto-neurons. } \\
\text { Sciatic nerve transection }\end{array}$ & $\begin{array}{l}\text { Dorsal root ganglia. } \\
\text { Sciatic nerve transection }\end{array}$ \\
\hline $1.5 \mathrm{~h}$ & 0.0 & $1.3(0-2.5)$ & 0.0 & 0.0 \\
$3 \mathrm{~h}$ & $33.5(24.5-42.0)$ & $1.0(0-1.6)$ & 0.0 & 0.0 \\
$6 \mathrm{~h}$ & 100 & $1.4(1.3-19)$ & 0.0 & $1.3(0.9-1.5)$ \\
$24 \mathrm{~h}$ & 100 & $19.0(11.0-23.8)$ & $59.5(50.0-69.9)$ & $55.4(48.2-59.5)$ \\
3 days & 100 & $4.2(4.0-6.1)$ & $57.4(49.2-80.0)$ & $60.2(45.5-63.8)$ \\
7 days & 100 & $0.0(0-1.2)$ & $50.0(47.5-68.9)$ & $52.1(42.1-60.5)$ \\
21 days & $(100)$ & $0.6(0-1.0)$ & $37.5(30.8-60.0)$ & $45.6(42.6-59.3)$
\end{tabular}

Value (100) means that although all remaining neurons at 21 days are labeled, cell death was immense (66.5\%). No significant cell death was at hand at other survival times. 


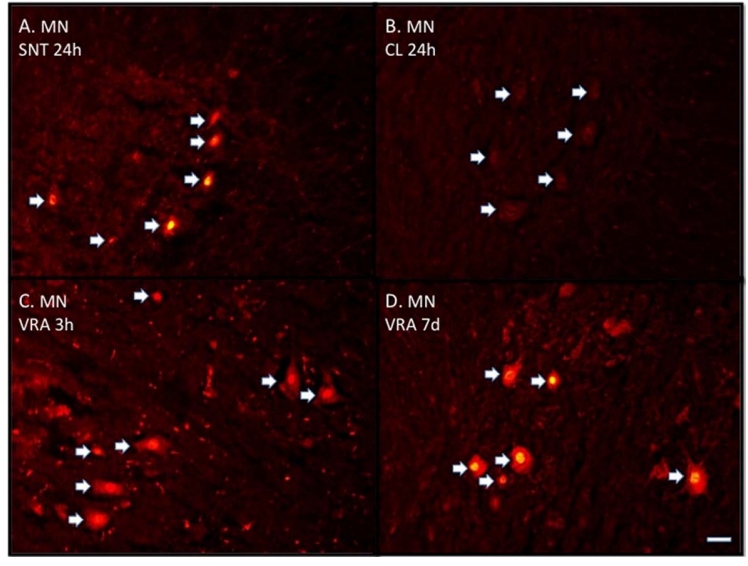

FIGURE 2 | (A-D) Immunofluorescence photomicrographs stained with ATF3 antibodies showing transverse sectioned spinal motoneurons (MN). (A) Shows labeled motoneurons (arrows) $24 \mathrm{~h}$ after sciatic nerve transection (SNT). (B) Shows unlabeled motoneurons on the contra-lateral side (CL) after SNT. (C) Shows labeled motoneurons $3 \mathrm{~h}$ after ventral root avulsion (VRA) and (D) still labeled motoneurons after 7 days. Scale bar $50 \mu \mathrm{m}$ (A-D).

described recently (Eggers et al., 2010). In humans, replantation of an avulsed ventral root after traumatic root avulsions has even been shown to be functional (Carlstedt et al., 1995). In order to further increase survival of $\mathrm{MN}$ after root avulsion, neurotrophins has also been added locally after replantation of the avulsed root into the spinal cord (Blits et al., 2004). If no replantation is made, the large majority of MN will not survive 3 weeks as shown in this study and also in other studies (Koliatsos et al., 1994; Hammarberg et al., 1998; Piehl et al., 1998). In DRG, the effects of neurotrophins for neuronal survival is unknown because axonal lesions of DRG neurons do not normally provoke cell death (Chew et al., 2008). Also in this study, no obvious decrease in number of DRG neurons was at hand after sciatic nerve lesion or DRA. A clear ATF3 expression could only be seen after the peripheral axotomy, which indicates that ATF3 expression does not play a crucial role for the survival of DRG neurons.

In this study a few DRG neurons were found to be ATF3 labeled also after sham operation with no dorsal root lesion, thus indicating that even preparation for a DRA can cause ATF3 labeling. In the sham operations of the present study, only paraspinal muscles and skin were removed and no laminectomy was performed. However, the sham operation results in an axotomy of peripheral nerve branches originating in overlaying skin and paraspinal muscle afferents, which then represents a peripheral axotomy of DRG neurons. In contrast to the DRG neurons, $\mathrm{MN}$ in the lateral motor nuclei displayed no labeling and are not axotomized in this kind of sham operation. ATF3 labeling in DRG neurons has been described before in sham-operated animals, but in this case the animals were also subjected to a laminectomy(Huang et al., 2006).A laminectomy could, in addition to the peripheral axotomy of skin and muscle afferents, cause a direct trauma to the spinal cord and DRGs. The influence of the surgical procedure to ATF3 expression in DRG neurons is further emphasized in a study by Shortland et al. (2006). All results in experiments exploring the

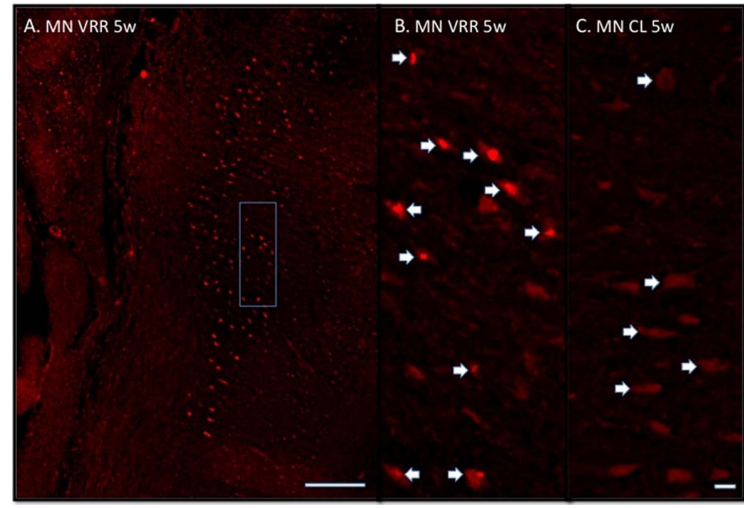

FIGURE 3 | (A,B) Immunofluorescence photomicrographs stained with ATF3 antibodies showing spinal motoneurons (MN) after ventral root avulsion followed by direct ventral root replantation (VRR) at 5 weeks post-operative survival time. (C) Unlesioned motoneurons located on the corresponding contra-lateral side (CL). A shows a longitudinal section of the lesion side from the spinal cord segments L5-6. The area depicted in (A) displays the area from which the motoneurons in (B) originate. Arrows indicate motoneurons sectioned in the nuclear plane. Note all the labeled motoneurons in $(\mathbf{A}, \mathbf{B})$. If no VRR is made the large majority of motoneurons will not survive 3 weeks. Scale bar $500 \mu \mathrm{m}$ (A) and $50 \mu \mathrm{m}$ (B,C).

regulation of ATF3 must then consider the fact that the surgical procedure itself could influence the outcome.

We found that only a relatively few DRG neurons in both animals and humans responded with ATF3 labeling after a DRA. The number of labeled neurons also decreased after only a few days, probably due to inappropriate signaling. The same kind of low and only transient ATF3 expression in DRG neurons is also seen after dorsal root transection, spinal cord compression and spinal cord hemisection (Huang et al., 2006). Generally, the regenerative response after a dorsal root lesion is very low (Carlstedt, 2010), thus indicating a linkage between ATF3 expression and regenerative capacity. In DRG neurons after SNT we found a marked and sustained ATF3 expression, and after this kind of nerve lesion regenerative capacity is good. Similarly, using microarray analysis, ATF3 expression in the DRG was highly up-regulated after a sciatic nerve crush in contrast to the lower expression after a dorsal root crush (Stam et al., 2007). In the present study, the correlation between regenerative capacity and ATF3 expression was also evident in MN which showed a marked ATF3 labeling after both SNT and VRA. MN show good regenerative capacity after both SNT and ventral root lesions, but also after other very proximal lesions even within the spinal cord (Lindå et al., 1985, 1992b; Cullheim et al., 1989). However, the large majority of $M N$ will die after 2-3 weeks following a root avulsion if no replantation is accomplished or neurotrophins added (Hammarberg et al., 2000). Replantation of the avulsed ventral root will, however, only produce a transient survival effect on the $\mathrm{MN}$, while many will die over the subsequent 2 months (Bergerot et al., 2004; Eggers et al., 2010). Thus, ATF3 expression does not protect $\mathrm{MN}$ from apoptotic cell death or is a prerequisite for survival after a lesion, but insteadATF3 expression indicates regenerative capability. ATF3 could be seen as a marker of ongoing regeneration in contrast to, for example, nitric oxide synthase (NOS), which is seen in MN only at a time when they are 
dying after a VRA (Piehl et al., 1998). NOS expression could not be seen after other lesion types or survival times (Piehl et al., 1998). NOS expression may then be seen as a marker indicating ongoing degeneration. Another example of the close correlation between ATF3 expression and regenerative capacity has been shown in cultured adult DRG neurons. Neurons obtained from rats that had undergone a spinal nerve injury showed more ATF3 expression and, in parallel, extend longer neuritis than DRG neurons from naive rats grown for the same period of time and under the exact same conditions (Seijffers et al., 2006). In contrast to the effect after a peripheral nerve lesion, a dorsal rhizotomy before culture of the DRG neurons had no effect on ATF3 expression or on the number of neurons extending neuritis relative to naive rat DRG neurons. This correlates with our findings showing that ATF3 expression is very scarce after a dorsal root lesion in contrast to a peripheral axotomy. Moreover, to test whether increased ATF3 by itself could increase the neurite growth, adult DRG neurons from naive rats were collected and ATF3 over expression was accomplished by ATF3 delivery to the neurons using a viral vector, and in this case neurite outgrowth was enhanced (Seijffers et al., 2006). In transgenic mice that constitutively express ATF3 in non-injured

\section{REFERENCES}

Averill, S., Michael, G. J., Shortland, P. J., Leavesley, R. C., King, V. R., Bradbury, E. J., and McMahon, S. B.(2004). NGF and GDNF ameliorate the increase in ATF3 expression which occurs in dorsal root ganglion cells in response to peripheral nerve injury. Eur. J. Neurosci. 19, 1437-1445.

Bergerot, A., Shortland, P. J., Anand, P., Hunt, S. P., and Carlstedt, T. (2004). Co-tratment with riluzole and GDNF is necessary for functional recovery after ventral root avulsion injury. Exp. Neurol. 187, 359-366.

Blits, B., Carlstedt, T., Ruitenberg, M. J., de Winter, F., Hermens, W. T. J. M. C., Dijkhuizen, P. A., Claasens, J. W. C., Eggers, R., van der Sluis, R., Tenenbaum, L., Boer, G. J, and Verhaagen, J. (2004). Rescue and sprouting of motoneurons following ventral root avulsion and reimplantation combined with intraspinal adeno-associated viral vector-mediated expression of glial cell line-derived neurotrophic factor or brain-derived neurotrophic factor. Exp. Neurol. 189, 303-316.

Carlstedt, T. (2010). Perspectives on the treatment of the longitudinal spinal cord injury. Front. Neurol. 111, 1-4. doi: 10.3389/fneur.2010.00011

Carlstedt, T., Grane, P., Hallin, R., and Noren, G. (1995). Return of function after spinal cord implantation of avulsed spinal nerve roots. Lancet 346, 1323-1325.
Carlstedt, T., Lindå, H., Cullheim, S., and Risling, M. (1986). Reinnervation of hind limb muscles after ventral root avulsion and implantation in the lumbar spinal cord of the adult rat. Acta Physiol. Scand. 128, 645-646.

Chai, H., Wu, W., So, K. F., and Yip, H. K. (2000). Survival and regeneration of motoneurons in adult rats by reimplantation ventral root following spinal root avulsion. Neuroreport 11, 1249-1252.

Chen, B. P., Liang, G., Whelan, J., and Hai, T. (1994). ATF3 and ATF3 delta Zip. Transcriptional repression versus activation by alternatively spliced isoforms. J. Biol. Chem. 269, 15819-15826.

Chen, B. P., Wolfgang, C. D., and Hai, T. (1996). Analysis of ATF3, a transcription factor induced by physiological stresses and modulated by gadd153/Chop10. Mol. Cell. Biol. 16, 1157-1168.

Chew, D. J., Leinster, V. H. L., Sakthithasan, M., Robson, M. L., Carlstedt, T., and Shortland, P. J. (2008). Cell death after dorsal root injury. Neurosci. Lett. 433, 231-234.

Chong, M. S., Reynolds, M. L., Irwin, N., Coggeshall, R. E., Emson, P. C., Benowitz, L. I., and Woolf, C. J. (1994). GAP-43 expression in primary sensory neurons following central axotomy. J. Neurosci. 14, 4375-4384.

Cullheim, S., Carlstedt, T., Lindå, H., Risling, M., and Ulfhake, B. (1989). Motoneurons reinnervate skeletal muscle after ventral root

adult DRG neurons, peripheral nerve regeneration is enhanced (Seijffers et al., 2007). Thus, ATF3 contributes to nerve regeneration by increasing the intrinsic growth state of injured neurons. A correlation between ATF3 expression and regenerative capacity was also seen after a delayed nerve repair after SNT. The number of $\mathrm{MN}$ and sensory neurons showing ATF3 labeling was higher, and the axonal outgrowth was longer, when the nerve was immediately repaired compared with delayed repair (Saito and Dahlin, 2008).

\section{CONCLUSION}

As is showed in this study, ATF3 could be a valuable and reliable marker for regenerative capability also in humans and used, for example, in other studies evaluating the time window for successful replantation of avulsed nerve roots.

\section{ACKNOWLEDGMENTS}

Authors are grateful to Thomas Carlstedt (Department of Hand Surgery, KarolinskaInstitutet, Södersjukhuset, Stockholm, Sweden) for giving us the opportunity of examining traumatically avulsed human dorsal root ganglias. Authors are also indebted to Ms. M. Angeria for excellent technical assistance.

implantation into the spinal cord of the cat. Neuroscience 29, 725-733.

Eggers, R., Tannemaat, M. R., Ehlert, E. M., and Verhaagen, J. (2010). A spatio-temporal analysis of motoneuron survival, axonal regeneration and neurotrophic factor expression after lumbar ventral root avulsion and implantation. Exp. Neurol. 223, 2017-2220.

Hammarberg, H., Lidman, O., Lundberg, C., Eltayeb, S. Y., Gielen, A. W., Muhallab, S., Svenningsson, A., Lindå, H., van Der Meide, P. H., Cullheim, S., Olsson, T., and Piehl, F. (2000). Neuroprotection by encephalomyelitis: rescue of mechanically injured neurons and neurotrophin production by CNSinfiltrating $\mathrm{T}$ and natural killer cells. J. Neurosci. 20, 5283-5291.

Hammarberg, H, Risling, M., Hökfelt, T., Cullheim, S., and Piehl, F. (1998). Expression of insulin-like growth factors and corresponding binding proteins (IGFBP 1-6) in rat spinal cord and peripheral nerve after axonal injuries. J. Comp. Neurol. 400, 57-72.

Herdegen, T., Leah, J. D., Manisali, A., Bravo, R., and Zimmermann, M. (1991). c-JUN-like immunoreactivity in the CNS of the adult rat: basal and transynaptically induced expression of an immediate-early gene. Neuroscience 41, 643-654.

Hoang, T. X., and Havton, L. A. (2006). A single re-implanted ventral root exerts neurotropic effects over multiple spinal cord segments in the adult rat. Exp. Brain Res. 169, 208-217.
Huang, W. L., Robson, D., Liu, M. C., King, V. R., Averill, S., Shortland, P. J., and Priestley, J. V. (2006). Spinal cord compression and dorsal root injury cause up-regulation of activating transcription factor-3 in large diameter dorsal root ganglion neurons. Eur. J. Neurosci. 23, 273-278.

Hunt, D., Hossain-Ibrahim, K., Mason, M. R., Coffin, R. S., Lieberman, A. R., Winterbottom, J., and Anderson, P. N. (2004). ATF3 upregulation in glia during Wallerian degeneration: differential expression in peripheral nerves and CNS white matter. BMC Neurosci. 5, 9. doi: 10.1186/14712202-5-9

Kataoka K., Kanje, M., and Dahlin, L. B. (2007). Induction of activating transcription factor 3 after different sciatic nerve injuries in adult rats. Scand. J. Plast. Reconstr. Surg. Hand. Surg. 41, 158-166.

Kenney, A. M., and Kocsis, J. D. (1997a). Timing of c-jun protein induction in lumbar dorsal root ganglia after sciatic nerve transection varies with lesion distance. Brain Res. 751, 90 95.

Kenney, A. M., and Kocsis, J. D. (1997b). Temporal variability of jun family transcription factor levels in peripherally or centrally transected adult rat dorsal root ganglia. Brain Res. Mol. Brain Res. 52, 53-61.

Koliatsos, V. E., Price, W. L., Pardo, C. A., and Price, D. L. (1994). Ventral root avulsion: an experimental model of death of adult motor neurons. J. Comp. Neurol.342, 35-44. 
Leah, J. D., Herdegen, T.,and Bravo, R. (1991). Selective expression of Jun proteins following axotomy and axonal transport block in peripheral nerves in the rat: evidence for a role in the regeneration process. Brain Res. 566, 198-207.

Lindå, H., Piehl, F., Dagerlind, Å., Verge, V. M., Arvidsson, U., Cullheim, S., Risling, M., Ulfhake, B., and Hökfelt, T. (1992a). Expression of GAP43 mRNA in the adult mammalian spinal cord under normal conditions and after different types of lesions, with special reference to motoneurons. Exp. Brain Res. 91, 284-295.

Lindå, H., Cullheim, S., and Risling, M. (1992b). A light and electron microscopic study of intracellularly HRPlabeled lumbar motoneurons after intramedullary axotomy in the adult cat. J. Comp. Neurol. 318, 188-208.

Lindå, H., Risling, M., and Cullheim, S. (1985). 'Dendraxons' in regenerating motoneurons in the cat: do dendrites generate new axons after central axotomy? Brain Res. 358, 329-333.

Mason, M. R., Lieberman, A. R., and Andersson P. N.(2003). Corticospinal neurons up-regulate a range of growth-associated genes following intracortical, but not spinal, axotomy. Eur. J. Neurosci. 18, 789-802.

Mayumi-Matsuda, K., Kojima, S., Nakayama, T., Suzuki, H., and Sakata, T. (1999). Scanning gene expression during neuronal cell death evoked by nerve growth factor depletion. Biochim. Biophys. Acta 1489, 293-302.

Nakagomi, S., Suzuki, Y., Namikawa, K., Kiryu-Seo, S., and Kiyama, H. (2003). Expression of the activating transcription factor 3 prevents cJun N-terminal kinase-induced neuronal death by promoting heat shock protein 27 expression and Akt activation. J. Neurosci. 23, 5187-5196.

Novikov, L., Novikova, L., and Kellerth, J. O. (1995). Brain Derived neurotrophic factor promotes survival and blocks nitric oxide synthase expression in adult rat spinal motoneurons after ventral root avulsion. Neurosci. Lett. 200, 45-48.

Parsadanian A, Pan Y, Li W, Myckatyn TM, and Brakefield D. (2006). Astrocyte-derived transgene GDNF promotes complete and long-term survival of adult facial motoneurons following avulsion and differentially regulates the expression of transcription factors of AP-1 and ATF/CREB families. Exp. Neurol. 200, 26-37.

Piehl F., Hammarberg, H., Tabar, G. Hökfelt, T., and Cullheim, S. (1998). Changes in the mRNA expression pattern, with special reference to calcitonin gene-related peptide, after axonal injuries in rat motoneurons depends on age and type of injury. Exp. Brain Res. 119, 191-204.

Rich, K. M., Alexander, T. D., Pryor, J. C., and Hollowell, J. P. (1989). Nerve growth factor enhances regeneration through silicone chambers. Exp. Neurol. 105, 162-170.

Rich, K. M., Luszczynski, J. R., Osborne, P. A., and Johnson, E. M. Jr. (1987). Nerve growth factor protects adult sensory neurons from cell death and atrophy caused by nerve injury. $J$. Neurocytol. 16, 261-268.

Saito, H., and Dahlin, L. B. (2008). Expression of ATF3 and axonal outgrowth are impaired after delayed nerve repair. BMC Neurosci. 9, 88. doi:10.1186/1471-2202-9-88

Seijffers, R., Allchorne, A. J., and Woolf C. J. (2006). The transcription factor ATF-3 promotes neurite outgrowth. Mol. Cell. Neurosci. 32, 143-154.
Seijffers, R., Mills, C. D., and Woolf, C. J. (2007). ATF3 increases the intrinsic growth state of DRG neurons to enhance peripheral nerve regeneration. J. Neurosci. 27, 79117920.

Sheng, M., and Greenberg, M. E. (1990). The regulation and function of cfos and other immediate early genes in the nervous system. Neuron 4, 477-485.

Shortland, P. J., Baytug, B. Krzyzanowska, A., McMahon, S. B., Priestly, J. V., and Averill, S. (2006). ATF3 expression in L4 dorsal root ganglion neurons after L5 spinal nerve transection. Eur. J. Neurosci. 23, 365-373.

Stam, F. J., Macgillavry, H. D., Armstrong, N. J., de Gunst, M. C. M., Zhang, Y., van Kesteren, R. E., Smit, A. B., and Verhaagen, J. (2007). Identification of candidate transcriptional modulators involved i successful regeneration after nerve injury. Eur. J. Neurosci. 25,36293637.

Tsujino, H., Kondo, E., Fukuoka, A., Dai, Y., Tokunaga, A., Miki, K., Yonenobu, K., Ochi, T., and Noguchi, K. (2000). Activating transcription factor 3 (ATF3) induction by axotomy in sensory and motoneurons: a novel neuronal marker of nerve injury. Mol. Cell. Neurosci. 15, 170182.

Vlug, A. S, Teuling, E., Haasdijk, E. D., French, P., Hoogenraad, C. C., and Jaarsma, D. (2005). ATF3 expression precedes death of spinal motoneurons in amyotrophic lateral sclerosis-SOD1 transgenic mice and correlates with c-jun phosphorylation, CHOP expression, somatodendritic ubiquitination and Golgi fragmentation. Eur. J. Neurosci. 22, 1881-1894.
Wu, W. (1996). Potential roles of gene expression change in adult rat spinal motoneurons following axonal injury: a comparison among c-jun, off-affinity nerve growth factor receptor (LNGFR), and nitric oxide synthase (NOS). Exp. Neurol. 141, 190-200.

Wu, W., Li L., Yick, L. W., Chai, H., Xie, Y., Yang, Y., Prevette, D. M., and Oppenheim, R. W. (2003). GDNF and BDNF alter the expression of neuronal NOS, c-Jun, and p75 and prevent motoneuron death following spinal root avulsion in adult rats. J. Neurotrauma 20, 603-612.

Conflict of Interest Statement: The authors declare that the research was conducted in the absence of any commercial or financial relationships that could be construed as a potential conflict of interest.

Received: 06 February 2011; paper pending published: 16 March 2011; accepted: 04 May 2011; published online: 17 May 2011.

Citation: Lindå H, Sköld $M K$ and Ochsmann $T$ (2011) Activating transcription factor 3, a useful marker for regenerative response after nerve root injury. Front. Neur. 2:30. doi: 10.3389/fneur.2011.00030

This article was submitted to Frontiers in Neurotrauma, a specialty of Frontiers in Neurology.

Copyright (c) 2011 Lindå, Sköld and Ochsmann. This is an open-access article subject to a non-exclusive license between the authors and Frontiers Media $S A$, which permits use, distribution and reproduction in other forums, provided the original authors and source are credited and other Frontiers conditions are complied with. 